\title{
Weak and Strong Convergence Theorems for Zeroes of Accretive Operators in Banach Spaces
}

\author{
Yanlai Song ${ }^{1}$ and Luchuan Ceng ${ }^{2}$ \\ ${ }^{1}$ Department of Mathematics, Shanghai Normal University, Shanghai 200234, China \\ ${ }^{2}$ Department of Mathematics, Shanghai Normal University, Scientific Computing Key Laboratory of Shanghai University, \\ Shanghai 200234, China
}

Correspondence should be addressed to Luchuan Ceng; zenglc@hotmail.com

Received 22 October 2013; Accepted 28 January 2014; Published 13 March 2014

Academic Editor: Alberto Cabada

Copyright (C) 2014 Y. Song and L. Ceng. This is an open access article distributed under the Creative Commons Attribution License, which permits unrestricted use, distribution, and reproduction in any medium, provided the original work is properly cited.

\begin{abstract}
The purpose of this paper is to present two new forward-backward splitting schemes with relaxations and errors for finding a common element of the set of solutions to the variational inclusion problem with two accretive operators and the set of fixed points of nonexpansive mappings in infinite-dimensional Banach spaces. Under mild conditions, some weak and strong convergence theorems for approximating this common elements are proved. The methods in the paper are novel and different from those in the early and recent literature. Our results can be viewed as the improvement, supplementation, development, and extension of the corresponding results in the very recent literature.
\end{abstract}

\section{Introduction}

Let $C$ be a nonempty closed convex subset of a real Hilbert space $H$. Let $A: C \rightarrow H$ be a single-valued nonlinear mapping and let $B: H \rightarrow 2^{H}$ be a multivalued mapping. The so-called quasivariational inclusion problem is to find a $z \in H$ such that

$$
0 \in(A+B) z .
$$

The set of solutions of (1) is denoted by $(A+B)^{-1}(0)$. A number of problems arising in structural analysis, mechanics, and economics can be studied in the framework of this kind of variational inclusions; see, for instance, [1-4]. The problem (1) includes many problems as special cases as follows.

(1) If $B=\partial \phi: H \rightarrow 2^{H}$, where $\phi: H \rightarrow \mathbb{R} \cup\{+\infty\}$ is a proper convex lower semicontinuous function and $\partial \phi$ is the subdifferential of $\phi$, then the variational inclusion problem (1) is equivalent to find $u \in H$ such that

$$
\langle A u, y-u\rangle+\phi(y)-\phi(u) \geq 0, \quad \forall y \in H,
$$

which is called the mixed quasivariational inequality (see, Noor [5]).
(2) If $B=\partial \delta_{C}$, where $C$ is a nonempty closed convex subset of $H$ and $\delta_{C}: H \rightarrow[0, \infty]$ is the indicator function of $C$, that is,

$$
\delta_{C}= \begin{cases}0, & x \in C, \\ +\infty, & x \notin C,\end{cases}
$$

then the variational inclusion problem (1) is equivalent to find $u \in C$ such that

$$
\langle A u, v-u\rangle \geq 0, \quad \forall v \in C .
$$

This problem is called Hartman-Stampacchia variational inequality (see, e.g., [6]).

In [7], Zhang et al. investigated the problem of finding a common element of the set of solutions to the inclusion problem and the set of fixed points of nonexpansive mappings by considering the following iterative algorithm:

$$
\begin{gathered}
y_{n}=J_{M, \lambda}\left(x_{n}-\lambda A x_{n}\right), \\
x_{n+1}=\alpha_{n} x+\left(1-\alpha_{n}\right) S y_{n},
\end{gathered}
$$

where $A: H \rightarrow H$ is an $\alpha$-cocoercive mapping, $M$ : $H \rightarrow 2^{H}$ is a maximal monotone mapping, $S: H \rightarrow H$ 
is a nonexpansive mapping, and $\left\{\alpha_{n}\right\}$ is a sequence in $[0,1]$. Under mild conditions, they obtained a strong convergence theorem.

In [8], Manaka and Takahashi introduced the following iteration:

$$
\begin{array}{r}
x_{1} \in C, \quad x_{n+1}=\alpha_{n} x_{n}+\left(1-\alpha_{n}\right) S J_{\lambda_{n}}\left(I-\lambda_{n} A\right) x_{n}, \\
n \geq 1,
\end{array}
$$

where $\left\{\alpha_{n}\right\}$ is a sequence in $(0,1),\left\{\lambda_{n}\right\}$ is a positive sequence, $S: C \rightarrow C$ is a nonexpansive mapping, $A: C \rightarrow H$ is an inversely strongly monotone mapping, $B: D(B) \subset C \rightarrow 2^{H}$ is a maximal monotone operator, and $J_{\lambda_{n}}=\left(I+\lambda_{n} B\right)^{-1}$ is the resolvent of $B$. They showed that the sequence $\left\{x_{n}\right\}$ generated in (6) converges weakly to some $z \in(A+B)^{-1}(0) \cap F(S)$ provided that the control sequence satisfies some restrictions.

It is well known that, the quasivariational inclusion problem in the setting of Hilbert spaces has been extensively studied in the literature; see, for instance, [3-14]. However, there is little work in the existing literature on this problem in the setting of Banach spaces (though there were some work on finding a common zero of a finite family of accretive operators [15-17]). The main difficulties are due to the fact that the inner product structure of a Hilbert space fails to be true in a Banach space. To overcome these difficulties, López et al. [18] use the new technique to carry out certain initiative investigations on splitting methods for accretive operators in Banach spaces. They considered the following algorithms with errors in Banach spaces:

$$
\begin{gathered}
x_{n+1}=\left(1-\alpha_{n}\right) x_{n}+\alpha_{n}\left(J_{r_{n}}^{B}\left(x_{n}-r_{n}\left(A x_{n}+a_{n}\right)\right)+b_{n}\right), \\
x_{n+1}=\alpha_{n} u+\left(1-\alpha_{n}\right)\left(J_{r_{n}}^{B}\left(x_{n}-r_{n}\left(A x_{n}+a_{n}\right)\right)+b_{n}\right),
\end{gathered}
$$

where $u \in E,\left\{a_{n}\right\},\left\{b_{n}\right\} \subset E$, and $J_{r_{n}}^{B}=\left(I+r_{n} B\right)^{-1}$ are the resolvent of $B$. Then they studied the weak and strong convergence of the algorithms (7) and (8), respectively.

Motivated and inspired by Zhang et al. [7], Manaka and Takahashi [8], López et al. [18], and Cho et al. [19], the purpose of this paper is to introduce two iterative forward-backward splitting methods for finding a common element of the set of solutions of the variational inclusion problem (1) with $m$-accretive operators and inverse strongly accretive operators and the set of fixed points of nonexpansive mappings in the setting of Banach space. Under suitable conditions, some weak and strong convergence theorems for approximating to this common elements are proved. The results presented in the paper not only improve and extend the main result in Zhang et al. [7], but also replenish and extend the corresponding results in Manaka and Takahashi [8], López et al. [18], and Cho et al. [19].

\section{Preliminaries}

Throughout this paper, we denote by $E$ and $E^{*}$ a real Banach space and the dual space of $E$, respectively. Let $C$ be a subset of $E$ and $T$ be a mapping on $C$. We use $F(T)$ to denote the set of fixed points of $T$. Let $q>1$ be a real number. The generalized duality mapping $J_{q}: E \rightarrow 2^{E^{*}}$ is defined by

$$
J_{q}(x)=\left\{x^{*} \in E^{*}:\left\langle x, x^{*}\right\rangle=\|x\|^{q},\left\|x^{*}\right\|=\|x\|^{q-1}\right\}
$$

for all $x \in E$, where $\langle\cdot, \cdot\rangle$ denotes the generalized duality pairing between $E$ and $E^{*}$. In particular, $J=J_{2}$ is called the normalized duality mapping and $J_{q}(x)=\|x\|^{q-2} J_{2}(x)$ for $x \neq 0$. If $E$ is a Hilbert space, then $J=I$, where $I$ is the identity mapping. It is well known that if $E$ is smooth, then $J_{q}$ is singlevalued, which is denoted by $j_{q}$.

The norm of a Banach space $E$ is said to be Gâteaux differentiable if the limit

$$
\lim _{t \rightarrow 0} \frac{\|x+t y\|-\|x\|}{t}
$$

exists for all $x, y$ on the unit sphere $S(E)=\{x \in E:\|x\|=1\}$. If, for each $y \in S(E)$, the limit (10) is uniformly attained for $x \in S(E)$, then the norm of $E$ is said to be uniformly Gâteaux differentiable. The norm of $E$ is said to be Fréchet differentiable if, for each $x \in S(E)$, the limit (10) is attained uniformly for $y \in S(E)$.

Let $\rho_{E}:[0,1) \rightarrow[0,1)$ be the modulus of smoothness of $E$ defined by

$$
\begin{aligned}
\rho_{E}(t)=\sup \left\{\frac{1}{2}(\|x+y\|+\|x-y\|)\right. \\
-1: x \in S(E),\|y\| \leq t\} .
\end{aligned}
$$

A Banach space $E$ is said to be uniformly smooth if $\rho_{E}(t) / t \rightarrow 0$ as $t \rightarrow 0$. Let $q>1$. A Banach space $E$ is said to be $q$-uniformly smooth, if there exists a fixed constant $c>0$ such that $\rho_{E}(t) \leq c t^{q}$. It is well known that $E$ is uniformly smooth if and only if the norm of $E$ is uniformly Fréchet differentiable. If $E$ is $q$-uniformly smooth, then $q \leq 2$ and $E$ is uniformly smooth, and hence the norm of $E$ is uniformly Fréchet differentiable, in particular, the norm of $E$ is Fréchet differentiable. Typical examples of both uniformly convex and uniformly smooth Banach spaces are $L^{p}$, where $p>1$. More precisely, $L^{p}$ is $\min \{p, 2\}$-uniformly smooth for every $p>1$.

A Banach space $E$ is said to be uniformly convex if, for any $\varepsilon \in(0,2]$, there exists $\delta>0$ such that, for any $x, y \in$ $S(E),\|x-y\| \geq \varepsilon$ implies $\|(x+y) / 2\| \leq 1-\delta$. It is known that a uniformly convex Banach space is reflexive and strictly convex.

A Banach space is said to have the Kadec-Klee property if for every sequence $\left\{x_{n}\right\}$ in $E, x_{n} \rightarrow x$ and $\left\|x_{n}\right\| \rightarrow\|x\|$ together imply $\left\|x_{n}-x\right\| \rightarrow 0$.

A Banach space $E$ is said to satisfy Opial's condition if for any sequence $\left\{x_{n}\right\}$ in $E$ the condition that $\left\{x_{n}\right\}$ converges weakly to $x \in E$ implies that the inequality

$$
\liminf _{n \rightarrow \infty}\left\|x_{n}-x\right\| \leq \liminf _{n \rightarrow \infty}\left\|x_{n}-y\right\|
$$

holds for every $y \in E$ with $y \neq x$. 
Definition 1. A mapping $T: C \rightarrow E$ is said to be

(1) nonexpansive if

$$
\|T x-T y\| \leq\|x-y\| \quad \forall x, y \in C ;
$$

(2) $r$-contractive if for all $x, y \in C$, there exists $r \in(0,1)$ such that

$$
\|T x-T y\| \leq r\|x-y\|
$$

(3) accretive if for all $x, y \in C$, there exists $j_{q}(x-y) \in$ $J_{q}(x-y)$ such that

$$
\left\langle T x-T y, j_{q}(x-y)\right\rangle \geq 0 ;
$$

(4) $\eta$-strongly accretive if for all $x, y \in C$, there exists $\eta>$ 0 and $j_{q}(x-y) \in J_{q}(x-y)$ such that

$$
\left\langle T x-T y, j_{q}(x-y)\right\rangle \geq \eta\|x-y\|^{q} ;
$$

(5) $\mu$-inverse strongly accretive if for all $x, y \in C$, there exists $\mu>0$ and $j_{q}(x-y) \in J_{q}(x-y)$ such that

$$
\left\langle T x-T y, j_{q}(x-y)\right\rangle \geq \mu\|T x-T y\|^{q} .
$$

Definition 2. A set-valued mapping $T: D(T) \subseteq E \rightarrow 2^{E}$ is said to be

(1) accretive if for any $x, y \in D(T)$, there exists $j(x-y) \in$ $J(x-y)$, such that for all $u \in T(x)$ and $v \in T(y)$,

$$
\langle u-v, j(x-y)\rangle \geq 0
$$

(2) $m$-accretive if $T$ is accretive and $(I+\rho T)(D(T))=E$ for every (equivalently, for some) $\rho>0$, where $I$ is the identity mapping.

Let $M: D(M) \rightarrow 2^{E}$ be $m$-accretive. The mapping $J_{\rho}^{M}:$ $E \rightarrow D(M)$, defined by

$$
J_{\rho}^{M}(u)=(I+\rho M)^{-1}(u), \quad \forall u \in E,
$$

is called the resolvent operator associated with $M$, where $\rho$ is any positive number and $I$ is the identity mapping. It is well known that $J_{\rho}^{M}$ is single-valued and nonexpansive. lemmas.

In order to prove our main results, we need the following

Lemma 3 (see [20]). Let $E$ be a Banach space and $J_{q}$ be a generalize duality mapping. Then for any given $x, y \in E$, the following inequality holds:

$$
\begin{array}{r}
\|x+y\|^{q} \leq\|x\|^{q}+q\left\langle y, j_{q}(x+y)\right\rangle, \\
j_{q}(x+y) \in J_{q}(x+y) .
\end{array}
$$

In particular, we have, for any given $x, y \in E$,

$\|x+y\|^{2} \leq\|x\|^{2}+2\langle y, j(x+y)\rangle, \quad j(x+y) \in J(x+y)$.
Lemma 4 (see [21]). Let $\left\{\alpha_{n}\right\}$ be a sequence of nonnegative numbers satisfying the property:

$$
\alpha_{n+1} \leq\left(1-\gamma_{n}\right) \alpha_{n}+b_{n}+\gamma_{n} c_{n}, \quad n \in \mathbb{N},
$$

where $\left\{\gamma_{n}\right\},\left\{b_{n}\right\}$, and $\left\{c_{n}\right\}$ satisfy the restrictions:

(i) $\sum_{n=1}^{\infty} \gamma_{n}=\infty$,

(ii) $b_{n} \geq 0, \sum_{n=1}^{\infty} b_{n}<\infty$,

(iii) $\limsup _{n \rightarrow \infty} c_{n} \leq 0$.

Then, $\lim _{n \rightarrow \infty} \alpha_{n}=0$.

Lemma 5 (see [22]). Let $\left\{a_{n}\right\},\left\{b_{n}\right\}$, and $\left\{\delta_{n}\right\}$ be sequences of nonnegative real numbers satisfying the inequality

$$
a_{n+1} \leq\left(1+\delta_{n}\right) a_{n}+b_{n}, \quad \forall n=1,2, \ldots
$$

If $\sum_{n=0}^{\infty} \delta_{n}<\infty$ and $\sum_{n=0}^{\infty} b_{n}<\infty$, then $\lim _{n \rightarrow \infty} a_{n}$ exists. In particular, $\lim _{n \rightarrow \infty} a_{n}=0$ whenever there exists a subsequence $\left\{a_{n_{k}}\right\}$ in $\left\{a_{n}\right\}$ which strongly converges to zero.

Lemma 6 (see [20]). Let $1<p<\infty, q \in(1,2], r>0$ be given.

(i) If $E$ is uniformly convex, then there exists a continuous, strictly increasing, and convex function $\varphi:[0, \infty) \rightarrow$ $[0, \infty)$ with $\varphi(0)=0$ such that

$$
\begin{aligned}
\|\lambda x+(1-\lambda) y\|^{p} \leq & \lambda\|x\|^{p}+\lambda\|y\|^{p} \\
& -W_{p}(\lambda) \varphi(\|x-y\|), \\
& x, y \in B_{r}, 0 \leq \lambda \leq 1,
\end{aligned}
$$

where $W_{p}(\lambda)=\lambda^{p}(1-\lambda)+(1-\lambda)^{p} \lambda, B_{r}=\{z \in E:$ $\|z\| \leq r\}$.

(ii) If $E$ be a real q-uniformly smooth Banach space, then there exists a constant $C_{q}>0$ such that

$$
\|x+y\|^{q} \leq\|x\|^{q}+q\left\langle y, J_{q}(x)\right\rangle+C_{q}\|y\|^{q}, \quad \forall x, y \in E .
$$

Lemma 7 (see [23]). Let $E$ be a uniformly convex Banach space, $C$ a closed convex subset of $E$, and $T: C \rightarrow E$ a nonexpansive mapping. Then, $I-T$ is demiclosed at zero.

Lemma 8 (see [24]). If $E$ is a uniformly convex Banach space and $C$ is a closed convex bounded subset of $E$, there is a continuous strictly increasing function $g:[0, \infty) \rightarrow[0, \infty)$ with $g(0)=0$ such that

$$
\begin{gathered}
g(\|S(t x+(1-t) y)-(\alpha S x+(1-\alpha) S y)\|) \\
\leq\|x-y\|-\|S x-S y\|
\end{gathered}
$$

for all $x, y \in C, t \in[0,1]$ and nonexpansive mappings $S: C \rightarrow$ E. 
Lemma 9 (see [25]). Let $E$ be a real reflexive Banach space such that its dual $E^{*}$ has the Kadec-Klee property. Let $\left\{x_{n}\right\}$ be a bounded sequence in $E$ and $x^{*}, y^{*} \in \omega_{w}\left(x_{n}\right)$; here $\omega_{w}\left(x_{n}\right)$ denotes the weak $w$-limit set of $\left\{x_{n}\right\}$. Suppose $\lim _{n \rightarrow \infty} \| t x_{n}+$ $(1-t) x^{*}-y^{*} \|$ exists for all $t \in[0,1]$. Then $x^{*}=y^{*}$.

Lemma 10. Let $C$ be a nonempty closed convex subset of a real q-uniformly smooth Banach space E. Let the mapping $A: C \rightarrow$ $E$ be a $\alpha$-inverse strongly accretive operator. Then the following inequality holds:

$$
\begin{aligned}
\|(I-\lambda A) x-(I-\lambda A) y\|^{q} \leq & \|x-y\|^{q} \\
& -\lambda\left(q \alpha-C_{q} \lambda^{q-1}\right)\|A x-A y\|^{q} .
\end{aligned}
$$

In particular, if $0<\lambda \leq\left(q \alpha / C_{q}\right)^{1 /(q-1)}$, then $\|I-\lambda A\|$ is nonexpansive.

Proof. Indeed, for all $x, y \in C$, it follows from Lemma 6 that

$$
\begin{aligned}
\|(I-\lambda A) x-(I-\lambda A) y\|^{q}= & \|(x-y)-\lambda(A x-A y)\|^{q} \\
\leq & \|x-y\|^{q} \\
& -q \lambda\left\langle A x-A y, j_{q}(x-y)\right\rangle \\
& +C_{q} \lambda^{q}\|A x-A y\|^{q} \\
\leq & \|x-y\|^{q}-q \alpha \lambda\|A x-A y\|^{q} \\
& +C_{q} \lambda^{q}\|A x-A y\|^{q} \\
\leq & \|x-y\|^{q} \\
& -\lambda\left(q \alpha-C_{q} \lambda^{q-1}\right)\|A x-A y\|^{q} .
\end{aligned}
$$

It is clear that if $0<\lambda \leq\left(q \alpha / C_{q}\right)^{1 /(q-1)}$, then $I-\lambda A$ is nonexpansive. This completes the proof.

Lemma 11. Assume that $C$ is a nonempty closed subset of a real uniformly convex and q-uniformly smooth Banach space $E$. Suppose that $A$ is a single-valued and $\alpha$-inverse strongly accretive operator for some $\alpha>0$ and $B$ is an $m$-accretive operator in $E$, with $C \subset D(A)$ and $C \subset D(B)$. Moreover, denote $J_{r}$ by

$$
J_{r} \equiv J_{r}^{B}=(I+r B)^{-1}
$$

and $T_{r}$ by

$$
T_{r}=J_{r}(I-r A)=(I+r B)^{-1}(I-r A) .
$$

Then, it is holds for all $r>0$ that $F\left(T_{r}\right)=(A+B)^{-1}(0)$.

Proof. From the definition of $T_{r}$, it follows that

$$
\begin{aligned}
x & =T_{r} x \Longleftrightarrow x=(I+r B)^{-1}(I-r A) x \\
& \Longleftrightarrow(I-r A) x \in(I+r B) x \\
& \Longleftrightarrow 0 \in(A+B) x .
\end{aligned}
$$

This lemma alludes to the fact that in order to solve the inclusion problem (1), it suffices to find a fixed point of $T_{r}$. Since $T_{r}$ is already split, an iterative algorithm for $T_{r}$ corresponds to a splitting algorithm for (1). However, to guarantee convergence (weak or strong) of an iterative algorithm for $T_{r}$, we need good metric properties of $T_{r}$ such as nonexpansivity. To this end, some relate geometric conditions on the underlying space $E$ are very necessary (see Lemmas 12 and 13 below).

Lemma 12 (see [18]). Assume that $C$ is a nonempty closed subset of a real uniformly convex and q-uniformly smooth Banach space E. Suppose that $A$ is a single-valued and $\alpha$ inverse strongly accretive operator for some $\alpha>0$ and $B$ is an $m$-accretive operator in $E$, with $C \subset D(A)$ and $C \subset D(B)$. Then, the following relations hold.

(i) Given $0<s \leq r$ and $x \in E$,

$$
\begin{aligned}
& \left\|T_{s} x-T_{r} x\right\| \leq\left|1-\frac{s}{r}\right|\left\|x-T_{r} x\right\|, \\
& \left\|x-T_{s} x\right\| \leq 2\left\|x-T_{r} x\right\| .
\end{aligned}
$$

(ii) Given $s>0$, there exists a continuous, strictly increasing, and convex function $\phi_{q}:[0, \infty) \rightarrow[0, \infty)$ with $\phi_{q}(0)=0$ such that for all $x, y \in B_{s}$,

$$
\begin{aligned}
\left\|T_{r} x-T_{r} y\right\|^{q} \leq & \|x-y\|^{q} \\
& -r\left(\alpha q-r^{q-1} C_{q}\right)\|A x-A y\|^{q} \\
& -\phi_{q}\left(\|\left(I-J_{r}\right)(I-r A) x-\left(I-J_{r}\right)\right. \\
& \times(I-r A) y \|) .
\end{aligned}
$$

Lemma 13. Assume that $C$ is a nonempty closed subset of a real uniformly convex and q-uniformly smooth Banach space $E$. Suppose that $S$ is a nonexpansive mapping and $A$ is a singlevalued and $\alpha$-inverse strongly accretive operator for some $\alpha>$ 0 and $B$ is a m-accretive operator in $E$, with $C \subset D(A)$ and $C \subset D(B)$. Assume $0<r<\left(q \alpha / C_{q}\right)^{1 /(q-1)}$. Then $F\left(S T_{r}\right)=$ $F(S) \cap F\left(T_{r}\right)$.

Proof. Suppose that $x_{1} \in F\left(S T_{r}\right)$, it is sufficient to show that $x_{1} \in F(S) \cap F\left(T_{r}\right)$. Indeed, for $x_{2} \in F(S) \cap F\left(T_{r}\right)$, we have by Lemma 12 that

$$
\begin{aligned}
\left\|x_{1}-x_{2}\right\|^{q}= & \left\|S T_{r} x_{1}-S T_{r} x_{2}\right\|^{q} \\
\leq & \left\|T_{r} x_{1}-T_{r} x_{2}\right\|^{q} \\
\leq & \left\|x_{1}-x_{2}\right\|^{q}-r\left(\alpha q-r^{q-1} C_{q}\right) \\
& \times\left\|A x_{1}-A x_{2}\right\|^{q} \\
& \quad-\phi_{q}\left(\|\left(I-J_{r}\right)(I-r A) x_{1}\right. \\
& \quad-\left(I-J_{r}\right)(I-r A) x_{2} \| .
\end{aligned}
$$


The property of $\phi$ and the condition $0<r<\left(q \alpha / C_{q}\right)^{1 /(q-1)}$ together imply that

$$
\begin{aligned}
\left\|A x_{1}-A x_{2}\right\| & =\left\|\left(I-J_{r}\right)(I-r A) x_{1}-\left(I-J_{r}\right)(I-r A) x_{2}\right\| \\
& =0 .
\end{aligned}
$$

It turns out that

$$
\left\|x_{1}-T_{r} x_{1}-x_{2}+T_{r} x_{2}\right\|=0
$$

which imply

$$
T_{r} x_{1}=x_{1} .
$$

Noticing the assumption of $x_{1}=S T_{r} x_{1}$, we can deduce $x_{1}=$ $S x_{1}$. This means that $x_{1} \in F(S) \cap F\left(T_{r}\right)$.

Next we give a weak convergence theorem in a Banach space $E$.

\section{Main Results}

Theorem 14. Let $E$ be a uniformly convex and q-uniformly smooth Banach space. Let $A: E \rightarrow E$ be $\alpha$-inverse strongly accretive, let $B: E \rightarrow 2^{E}$ be $m$-accretive, and let $S: E \rightarrow E$ be nonexpansive. Assume that $F(S) \cap(A+B)^{-1}(0) \neq \emptyset$. We define a sequence $\left\{x_{n}\right\}$ by the perturbed iterative scheme:

$$
\begin{array}{r}
x_{n+1}=\left(1-\alpha_{n}\right) x_{n} \\
+\alpha_{n} S\left(J_{r_{n}}\left(x_{n}-r_{n}\left(A x_{n}+a_{n}\right)\right)+b_{n}\right), \\
\forall n \geq 1,
\end{array}
$$

where $J_{r_{n}}=\left(I+r_{n} B\right)^{-1},\left\{a_{n}\right\},\left\{b_{n}\right\} \subset E,\left\{\alpha_{n}\right\} \subset(0,1]$, and $\left\{r_{n}\right\} \subset(0,+\infty)$. Assume that

(i) $\sum_{n=1}^{\infty}\left\|a_{n}\right\|<\infty$ and $\sum_{n=1}^{\infty}\left\|b_{n}\right\|<\infty$;

(ii) $0<\liminf _{n \rightarrow \infty} \alpha_{n} \leq \lim \sup _{n \rightarrow \infty} \alpha_{n}<1$;

(iii) $0<\liminf _{n \rightarrow \infty} r_{n} \leq \lim \sup _{n \rightarrow \infty} r_{n}<\left(q \alpha / C_{q}\right)^{1 /(q-1)}$.

Then $\left\{x_{n}\right\}$ converges weakly to some point $\widehat{z} \in F(S) \cap(A+$ $B)^{-1}(0)$.

Proof. We divide the proof into several steps.

First we prove that $\lim _{n \rightarrow \infty}\left\|x_{n}-z\right\|$ exist for any point $z \in F(S) \cap(A+B)^{-1}(0)$

Putting $T_{n}=J_{r_{n}}\left(I-r_{n} A\right)=\left(I+r_{n} B\right)^{-1}\left(I-r_{n} A\right)$, one has

$$
S\left(J_{r_{n}}\left(x_{n}-r_{n}\left(A x_{n}+a_{n}\right)\right)+b_{n}\right)=S T_{n} x_{n}+g_{n},
$$

where

$$
g_{n}=S\left(J_{r_{n}}\left(x_{n}-r_{n}\left(A x_{n}+a_{n}\right)\right)+b_{n}\right)-S T_{n} x_{n} .
$$

Then the iterative formula (38) turns into the form

$$
x_{n+1}=\left(1-\alpha_{n}\right) x_{n}+\alpha_{n}\left(S T_{n} x_{n}+g_{n}\right) .
$$

Thus, by virtue of nonexpansivity of $S$ and $J_{r_{n}}$, it follows that

$$
\begin{aligned}
\left\|g_{n}\right\|= & \left\|S\left(J_{r_{n}}\left(x_{n}-r_{n}\left(A x_{n}+a_{n}\right)\right)+b_{n}\right)-S T_{n} x_{n}\right\| \\
\leq & \left\|J_{r_{n}}\left(x_{n}-r_{n}\left(A x_{n}+a_{n}\right)\right)-T_{n} x_{n}\right\| \\
& +\left\|b_{n}\right\| \leq r_{n}\left\|a_{n}\right\|+\left\|b_{n}\right\| .
\end{aligned}
$$

It follows from (42) and the condition (i) that

$$
\sum_{n=1}^{\infty}\left\|g_{n}\right\|<\infty
$$

Since $z \in F(S) \cap(A+B)^{-1}(0)$, we can deduce $z \in F(S) \cap F\left(T_{n}\right)$ due to Lemma 13. And $T_{n}$ is nonexpansive due to Lemma 12 and condition (iii). Therefore, we can get from (41) that

$$
\begin{aligned}
\left\|x_{n+1}-z\right\|= & \left(1-\alpha_{n}\right)\left\|x_{n}-z\right\| \\
& +\alpha_{n}\left\|S T_{n} x_{n}+g_{n}-z\right\| \\
\leq & \left(1-\alpha_{n}\right)\left\|x_{n}-z\right\|+\alpha_{n}\left\|S T_{n} x_{n}-z\right\| \\
& +\alpha_{n}\left\|g_{n}\right\| \leq\left(1-\alpha_{n}\right)\left\|x_{n}-z\right\| \\
& +\alpha_{n}\left\|x_{n}-z\right\|+\alpha_{n}\left\|g_{n}\right\| \\
\leq & \left\|x_{n}-z\right\|+\alpha_{n}\left\|g_{n}\right\| .
\end{aligned}
$$

In view of (43), (44), and Lemma 5, we can get that $\lim _{n \rightarrow \infty}\left\|x_{n}-z\right\|$ exists. Therefor $\left\{x_{n}\right\}$ is bounded.

Next, we show $\lim _{n \rightarrow \infty}\left\|T_{n} x_{n}-x_{n}\right\|=0$.

Let $M_{1}>0$ be such that $\left\|x_{n}\right\|<M_{1}$, for all $n \in \mathbb{N}$, and let $s=q\left(M_{1}+\|z\|\right)^{q-1}$. By (41), Lemmas 3, and 12, we have

$$
\begin{aligned}
\left\|x_{n+1}-z\right\|^{q}= & \left\|\left(1-\alpha_{n}\right)\left(x_{n}-z\right)+\alpha_{n}\left(S T_{n} x_{n}+g_{n}-z\right)\right\|^{q} \\
\leq & \left\|\left(1-\alpha_{n}\right)\left(x_{n}-z\right)+\alpha_{n}\left(S T_{n} x_{n}-z\right)\right\|^{q} \\
& +\alpha_{n} q\left\langle g_{n}, j_{q}\left(x_{n+1}-z\right)\right\rangle \\
\leq & \left(1-\alpha_{n}\right)\left\|x_{n}-z\right\|^{q}+\alpha_{n}\left\|S T_{n} x_{n}-z\right\|^{q} \\
& +\alpha_{n} q\left\|g_{n}\right\|\left\|x_{n+1}-z\right\|^{q-1} \\
\leq & \left(1-\alpha_{n}\right)\left\|x_{n}-z\right\|^{q}+\alpha_{n}\left\|T_{n} x_{n}-z\right\|^{q} \\
& +\alpha_{n} q\left\|g_{n}\right\|\left\|x_{n+1}-z\right\|^{q-1} \\
\leq & \left\|x_{n}-z\right\|^{q}-\alpha_{n} r_{n}\left(\alpha q-r_{n}^{q-1} C_{q}\right) \\
& \times\left\|A x_{n}-A z\right\|^{q}-\alpha_{n} \phi_{q} \\
& \times\left(\|\left(I-J_{r_{n}}\right)\left(I-r_{n} A\right) x_{n}\right. \\
& \left.\quad-\left(I-J_{r_{n}}\right)\left(I-r_{n} A\right) z \|\right)
\end{aligned}
$$




$$
\begin{aligned}
& +\alpha_{n} s\left\|g_{n}\right\| \leq\left\|x_{n}-z\right\|^{q}-\alpha_{n} r_{n}\left(\alpha q-r_{n}^{q-1} C_{q}\right) \\
& \times\left\|A x_{n}-A z\right\|^{q}-\alpha_{n} \phi_{q} \\
& \times\left(\left\|x_{n}-r_{n} A x_{n}-T_{n} x_{n}+r_{n} A z\right\|\right) \\
& +\alpha_{n} s\left\|g_{n}\right\| .
\end{aligned}
$$

Meanwhile, by the fact that $a^{r}-b^{r} \leq r a^{r-1}(a-b), \forall r \geq 1$, and (45), we can get that

$$
\begin{aligned}
& \alpha_{n} r_{n}\left(\alpha q-r_{n}^{q-1} C_{q}\right)\left\|A x_{n}-A z\right\|^{q} \\
& \quad+\alpha_{n} \phi_{q}\left(\left\|x_{n}-r_{n} A x_{n}-T_{n} x_{n}+r_{n} A z\right\|\right) \\
& \leq\left\|x_{n}-z\right\|^{q}-\left\|x_{n+1}-z\right\|^{q}+\alpha_{n} s\left\|g_{n}\right\| \\
& \leq q\left\|x_{n}-z\right\|^{q-1}\left(\left\|x_{n}-z\right\|-\left\|x_{n+1}-z\right\|\right) \\
&+\alpha_{n} s\left\|g_{n}\right\| .
\end{aligned}
$$

Thanks to the conditions of (ii),(iii), and (43) and existence of $\lim _{n \rightarrow \infty}\left\|x_{n}-z\right\|$, one has

$$
\lim _{n \rightarrow \infty}\left\|A x_{n}-A z\right\|=\lim _{n \rightarrow \infty}\left\|x_{n}-r_{n} A x_{n}-T_{n} x_{n}+r_{n} A z\right\|=0 .
$$

Consequently,

$$
\lim _{n \rightarrow \infty}\left\|T_{n} x_{n}-x_{n}\right\|=0
$$

Step 1. We prove $\lim _{n \rightarrow \infty}\left\|S T_{n} x_{n}-T_{n} x_{n}\right\|=0$.

Noticing (43) and Lemma 6, we have

$$
\begin{aligned}
\left\|x_{n+1}-z\right\|^{2}= & \left\|\left(1-\alpha_{n}\right)\left(x_{n}-z\right)+\alpha_{n}\left(S T_{n} x_{n}+g_{n}-z\right)\right\|^{2} \\
\leq & \left(1-\alpha_{n}\right)\left\|x_{n}-z\right\|^{2}+\alpha_{n}\left\|S T_{n} x_{n}+g_{n}-z\right\|^{2} \\
& -W_{2}\left(\alpha_{n}\right) \varphi\left(\left\|S T_{n} x_{n}+g_{n}-x_{n}\right\|\right) \\
\leq & \left(1-\alpha_{n}\right)\left\|x_{n}-z\right\|^{2} \\
& +\alpha_{n}\left(\left\|S T_{n} x_{n}-z\right\|^{2}+2\left\|S T_{n} x_{n}-z\right\|\left\|g_{n}\right\|\right. \\
& \left.+\left\|g_{n}\right\|^{2}\right) \\
& -W_{2}\left(\alpha_{n}\right) \varphi\left(\left\|S T_{n} x_{n}+g_{n}-x_{n}\right\|\right) \\
\leq & \left(1-\alpha_{n}\right)\left\|x_{n}-z\right\|^{2} \\
& +\alpha_{n}\left(\left\|x_{n}-z\right\|^{2}+2\left\|x_{n}-z\right\|\left\|g_{n}\right\|+\left\|g_{n}\right\|^{2}\right) \\
& -W_{2}\left(\alpha_{n}\right) \varphi\left(\left\|S T_{n} x_{n}+g_{n}-x_{n}\right\|\right) \\
\leq & \left\|x_{n}-z\right\|^{2}+2 \alpha_{n}\left\|x_{n}-z\right\|\left\|g_{n}\right\| \\
& +\alpha_{n}\left\|g_{n}\right\|^{2}-W_{2}\left(\alpha_{n}\right) \varphi\left(\left\|S T_{n} x_{n}+g_{n}-x_{n}\right\|\right) \\
\leq & \left\|x_{n}-z\right\|^{2}+2\left\|x_{n}-z\right\|\left\|g_{n}\right\|+\left\|g_{n}\right\|^{2} \\
& -W_{2}\left(\alpha_{n}\right) \varphi\left(\left\|S T_{n} x_{n}+g_{n}-x_{n}\right\|\right),
\end{aligned}
$$

which implies

$$
\begin{aligned}
& W_{2}\left(\alpha_{n}\right) \varphi\left(\left\|S T_{n} x_{n}+g_{n}-x_{n}\right\|\right) \\
& \leq\left\|x_{n}-z\right\|^{2}-\left\|x_{n+1}-z\right\|^{2}+2\left\|x_{n}-z\right\|\left\|g_{n}\right\| \\
& \quad+\left\|g_{n}\right\|^{2},
\end{aligned}
$$

where $W_{2}\left(\alpha_{n}\right)=\alpha_{n}\left(1-\alpha_{n}\right)$. From (50), assumptions (ii), (43), and existence of $\lim _{n \rightarrow \infty}\left\|x_{n}-z\right\|$, it turns out that

$$
\lim _{n \rightarrow \infty} \varphi\left(\left\|S T_{n} x_{n}+g_{n}-x_{n}\right\|\right)=0 .
$$

It follows from the property of $\varphi$ that

$$
\lim _{n \rightarrow \infty}\left\|S T_{n} x_{n}+g_{n}-x_{n}\right\|=0 .
$$

Noticing (43), we have

$$
\lim _{n \rightarrow \infty}\left\|S T_{n} x_{n}-x_{n}\right\|=0 .
$$

By (48) and (53), we get

$$
\lim _{n \rightarrow \infty}\left\|S T_{n} x_{n}-T_{n} x_{n}\right\|=0 .
$$

Step 2. We prove $\omega_{w}\left(x_{n}\right) \subset F(S) \cap(A+B)^{-1}(0)$.

Since $\lim \inf _{n \rightarrow \infty} r_{n}>0$, there exists $\varepsilon>0$ such that $r_{n} \geq$ $\varepsilon$ for all $n \geq 1$. Then, by Lemma 12 , we have

$$
\lim _{n \rightarrow \infty}\left\|T_{\varepsilon} x_{n}-x_{n}\right\| \leq 2 \lim _{n \rightarrow \infty}\left\|T_{n} x_{n}-x_{n}\right\|=0 .
$$

It follows from (48), (53), and (54) that

$$
\begin{aligned}
\left\|S T_{\varepsilon} x_{n}-x_{n}\right\| \leq & \left\|S T_{\varepsilon} x_{n}-S T_{n} x_{n}\right\|+\left\|S T_{n} x_{n}-x_{n}\right\| \\
\leq & \left\|T_{\varepsilon} x_{n}-T_{n} x_{n}\right\|+\left\|S T_{n} x_{n}-x_{n}\right\| \\
\leq & \left\|T_{\varepsilon} x_{n}-x_{n}\right\|+\left\|x_{n}-T_{n} x_{n}\right\| \\
& +\left\|S T_{n} x_{n}-x_{n}\right\| \longrightarrow 0 .
\end{aligned}
$$

By Lemmas 7 and 13, we get

$$
\omega_{w}\left(x_{n}\right) \subset F\left(S T_{\varepsilon}\right)=F(S) \bigcap(A+B)^{-1}(0) .
$$

Finally, we show that $\left\{x_{n}\right\}$ converges weakly to a fixed point of $\widehat{z} \in F(S) \cap(A+B)^{-1}(0)$.

Indeed, it suffices to show that $\omega_{w}\left(x_{n}\right)$ consists of exactly only one point. To this end, we suppose that two different points $\widehat{z}$ and $\widetilde{z}$ are in $\omega_{w}\left(x_{n}\right)$. Then there exist two different subsequences $\left\{n_{i}\right\}$ and $\left\{n_{j}\right\}$ such that $x_{n_{i}} \rightarrow \bar{z}$ and $x_{n_{j}} \rightarrow \widetilde{z}$ as $i \rightarrow \infty$ and $j \rightarrow \infty$. Define $S_{n, m}: D \rightarrow E$ by

$$
\begin{aligned}
S_{n, m} & =V_{n+m-1} V_{n+m-2} \cdots V_{n}, \\
V_{n} & =\left(1-\alpha_{n}\right) I+\alpha_{n} S T_{n} .
\end{aligned}
$$

Then $x_{n}$ can be written

$$
x_{n+m}=S_{n, m} x_{n}+c_{n, m},
$$


where

$$
\begin{gathered}
c_{n, m}=V_{n+m-1}\left(V_{n+m-2}\right. \\
\quad \times\left(\cdots V_{n+1}\left(V_{n} x_{n}+\alpha_{n} g_{n}\right)\right. \\
\left.\quad+\alpha_{n+1} g_{n+1} \cdots\right) \\
\left.+\alpha_{n+m-2} g_{n+m-2}\right) \\
+\alpha_{n+m-1} g_{n+m-1}-S_{n, m} x_{n} .
\end{gathered}
$$

Thanks to the nonexpansivity of $V_{n}$, we have

$$
\left\|c_{n, m}\right\| \leq \sum_{k=n}^{n+m-1}\left\|\alpha_{k} g_{k}\right\| \leq \sum_{k=n}^{n+m-1}\left\|g_{k}\right\| .
$$

It follows from (43) that

$$
\lim _{m, n \rightarrow \infty}\left\|c_{n, m}\right\| \longrightarrow 0
$$

Let

$$
\begin{gathered}
f_{n}(t)=\left\|t x_{n}+(1-t) \hat{z}-\tilde{z}\right\|, \\
d_{n, m}=S_{n, m}\left(t x_{n}+(1-t) \hat{z}\right)-\left(t S_{n, m} x_{n}+(1-t) \widehat{z}\right) .
\end{gathered}
$$

Apply Lemma 8 to the closed convex bounded subset $K$ := $\bar{c} o\left(\left\{x_{n}\right\} \cup\{\widehat{z}\}\right)$ to obtain

$$
\begin{aligned}
g\left(\left\|d_{n, m}\right\|\right) & \leq\left\|x_{n}-\widehat{z}\right\|-\left\|S_{n, m} x_{n}-S_{n, m} \widehat{z}\right\| \\
& \leq\left\|x_{n}-\widehat{z}\right\|-\left\|x_{n+m}-\widehat{z}-c_{n, m}\right\| \\
& \leq\left\|x_{n}-\widehat{z}\right\|-\left\|x_{n+m}-\widehat{z}\right\|+\left\|c_{n, m}\right\| .
\end{aligned}
$$

Since $\lim _{n \rightarrow \infty}\left\|x_{n}-\widehat{z}\right\|$ exists, (62) and (64) together imply that

$$
\lim _{m, n \rightarrow \infty} d_{n, m} \longrightarrow 0
$$

Furthermore, we have

$$
\begin{aligned}
f_{n+m}(t)= & \left\|t x_{n+m}+(1-t) \widehat{z}-\tilde{z}\right\| \\
\leq & \left\|d_{n, m}\right\|+\left\|S_{n, m}\left(t x_{n}+(1-t) \widehat{z}\right)-\widetilde{z}\right\| \\
& +t\left\|c_{m, n}\right\| \\
\leq & \left\|d_{n, m}\right\|+\left\|t x_{n}+(1-t) \widehat{z}-\tilde{z}\right\|+t\left\|c_{m, n}\right\| \\
= & \left\|d_{n, m}\right\|+f_{n}(t)+t\left\|c_{m, n}\right\| .
\end{aligned}
$$

After taking first $\limsup _{m \rightarrow \infty}$ and then $\liminf _{n \rightarrow \infty}$ in (66) and using (62) and (65), we get

$$
\begin{aligned}
\limsup _{m \rightarrow \infty} f_{m}(t) \leq & \liminf _{n \rightarrow \infty} f_{n}(t) \\
& +\lim _{m, n \rightarrow \infty}\left(\left\|d_{m, n}\right\|+\left\|c_{n, m}\right\|\right) \\
= & \liminf _{n \rightarrow \infty} f_{n}(t) .
\end{aligned}
$$

So that $\lim _{n \rightarrow \infty}\left\|t x_{n}+(1-t) \widehat{z}-\widetilde{z}\right\|$ exists for all $t \in[0,1]$. It follows from Lemma 9 that $\widehat{z}=\widetilde{z}$. This completes the proof.
Remark 15. Compared with the known results in the literature, our results are very different from those in the following aspects.

(i) Theorem 14 improves and extends Theorem 3.1 of Manaka and Takahashi [8] and Theorem 3 of Kamimura and Takahashi [9] from Hilbert spaces to uniformly convex and $q$-uniformly smooth Banach spaces.

(ii) Theorem 14 also improves and extends Theorem 3.6 of López et al. [18] from the problem of finding an element of $(A+B)^{-1}(0)$ to the problem of finding an element of $(A+B)^{-1}(0) \cap F(S)$.

Theorem 16. Let $E$ be a uniformly convex and q-uniformly smooth Banach space. Let $A: E \rightarrow E$ be $\alpha$-inverse strongly accretive, let $B: E \rightarrow 2^{E}$ be $m$-accretive, let $f: E \rightarrow E$ be $r$-contractive, and let $S: E \rightarrow E$ be nonexpansive. Assume that $F(S) \cap(A+B)^{-1}(0) \neq \emptyset$. We define a sequence $\left\{x_{n}\right\}$ by the perturbed iterative scheme:

$$
\begin{aligned}
x_{n+1}= & \alpha_{n} f\left(x_{n}\right)+\left(1-\alpha_{n}\right) \\
& \times S\left(J_{r_{n}}\left(x_{n}-r_{n}\left(A x_{n}+a_{n}\right)\right)+b_{n}\right),
\end{aligned}
$$

$\forall n \geq 1$

where $J_{r_{n}}=\left(I+r_{n} B\right)^{-1}$. Assume that $\left\{\alpha_{n}\right\} \subset[0,1],\left\{r_{n}\right\} \subset$ $(0,+\infty)$, and $\left\{a_{n}\right\},\left\{b_{n}\right\} \subset$ E satisfying the following conditions:

(i) $\sum_{n=1}^{\infty}\left\|a_{n}\right\|<\infty$ and $\sum_{n=1}^{\infty}\left\|b_{n}\right\|<\infty$;

(ii) $\sum_{n=1}^{\infty} \alpha_{n}=\infty \lim _{n \rightarrow \infty} \alpha_{n}=0$ and $\sum_{n=1}^{\infty}\left|\alpha_{n+1}-\alpha_{n}\right|<$ $\infty$;

(iii) $0<\liminf _{n \rightarrow \infty} r_{n} \leq \limsup _{n \rightarrow \infty} r_{n}<\left(q \alpha / C_{q}\right)^{1 /(q-1)}$ and $\sum_{n=1}^{\infty}\left|r_{n+1}-r_{n}\right|<\infty$.

Then $\left\{x_{n}\right\}$ converges strongly to some point $z \in F(S) \cap$ $(A+B)^{-1}(0)$, which is the unique solution of the variational inequality $\langle f(z)-z, j(p-z)\rangle \leq 0, \forall p \in F(S) \cap(A+B)^{-1}(0)$.

Proof. Let $\left\{y_{n}\right\}$ be a sequence generated by

$$
y_{n+1}=\alpha_{n} f\left(y_{n}\right)+\left(1-\alpha_{n}\right) S T_{n} y_{n}
$$

where $T_{n}:=J_{r_{n}}\left(I-r_{n} A\right)$. Hence to show the desired result, it suffices to prove that $y_{n} \rightarrow z$. Indeed, since $J_{r_{n}}$ and $\left(I-r_{n} A\right)$ are both nonexpansive under the condition of (iii), it follows that

$$
\begin{aligned}
& \| y_{n+1}- x_{n+1} \| \\
& \leq \| \alpha_{n} f\left(y_{n}\right)+\left(1-\alpha_{n}\right) S\left(J_{r_{n}}\left(y_{n}-r_{n} A y_{n}\right)\right) \\
& \quad-\alpha_{n} f\left(x_{n}\right)-\left(1-\alpha_{n}\right) \\
& \quad \times S\left(J_{r_{n}}\left(x_{n}-r_{n}\left(A x_{n}+a_{n}\right)\right)+b_{n}\right) \|
\end{aligned}
$$




$$
\begin{aligned}
\leq & \left(1-\alpha_{n}\right) \| S\left(J_{r_{n}}\left(y_{n}-r_{n} A y_{n}\right)\right) \\
& \quad-S\left(J_{r_{n}}\left(x_{n}-r_{n}\left(A x_{n}+a_{n}\right)\right)+b_{n}\right) \| \\
& +\alpha_{n} r\left\|y_{n}-x_{n}\right\| \\
\leq & \left(1-\alpha_{n}\right)\left\|J_{r_{n}}\left(y_{n}-r_{n} A y_{n}\right)-J_{r_{n}}\left(x_{n}-r_{n}\left(A x_{n}+a_{n}\right)\right)\right\| \\
& +\left\|b_{n}\right\|+\alpha_{n} r\left\|y_{n}-x_{n}\right\| \\
\leq & {\left[1-\alpha_{n}(1-r)\right]\left\|y_{n}-x_{n}\right\|+r_{n}\left\|a_{n}\right\|+\left\|b_{n}\right\| . }
\end{aligned}
$$

By virtue of Lemma 4 and (70), one has $\lim _{n \rightarrow \infty}\left\|y_{n}-x_{n}\right\|=0$.

We first prove that the sequences $\left\{y_{n}\right\}$ is bounded.

Thanks to (69) and Lemma 13, we have

$$
\begin{aligned}
\left\|y_{n+1}-z\right\|= & \left\|\alpha_{n} f\left(y_{n}\right)+\left(1-\alpha_{n}\right) S T_{n} y_{n}-z\right\| \\
\leq & \alpha_{n}\left\|f\left(y_{n}\right)-z\right\|+\left(1-\alpha_{n}\right)\left\|S T_{n} y_{n}-z\right\| \\
\leq & \alpha_{n}\left\|f\left(y_{n}\right)-f(z)\right\|+\alpha_{n}\|f(z)-z\| \\
& +\left(1-\alpha_{n}\right)\left\|S T_{n} y_{n}-z\right\| \\
\leq & \alpha_{n} r\left\|y_{n}-z\right\|+\alpha_{n}\|f(z)-z\| \\
& +\left(1-\alpha_{n}\right)\left\|y_{n}-z\right\| \\
= & {\left[1-\alpha_{n}(1-r)\right]\left\|y_{n}-z\right\|+\alpha_{n}\|f(z)-z\| } \\
\leq & \max \left\{\frac{\|f(z)-z\|}{1-r},\left\|y_{n}-z\right\|\right\} .
\end{aligned}
$$

By induction, we have

$$
\left\|y_{n}-z\right\| \leq \max \left\{\frac{\|f(z)-z\|}{1-r},\left\|y_{1}-z\right\|\right\}, \quad \forall n \geq 1 .
$$

Hence, $\left\{y_{n}\right\}$ is bounded, so are $\left\{f\left(y_{n}\right)\right\}$ and $\left\{T_{n}\left(y_{n}\right)\right\}$.

Next we prove that

$$
\lim _{n \rightarrow \infty}\left\|y_{n+1}-y_{n}\right\| \longrightarrow 0 .
$$

Putting $z_{n}=T_{n} y_{n}$, it follows from Lemma 12 that

$$
\begin{aligned}
\left\|z_{n+1}-z_{n}\right\|= & \left\|T_{n+1} y_{n+1}-T_{n} y_{n}\right\| \\
\leq & \left\|T_{n+1} y_{n+1}-T_{n} y_{n+1}\right\| \\
& +\left\|T_{n} y_{n+1}-T_{n} y_{n}\right\| \\
\leq & \left|1-\frac{r_{\alpha_{n}}}{r_{\beta_{n}}}\right|\left\|y_{n+1}-J_{r_{\beta_{n}}}\left(1-r_{\beta_{n}} A\right) y_{n+1}\right\| \\
& +\left\|y_{n+1}-y_{n}\right\| \\
\leq & \left|r_{\beta_{n}}-r_{\alpha_{n}}\right| \frac{\left\|y_{n+1}-J_{r_{\beta_{n}}}\left(1-r_{\beta_{n}} A\right) y_{n+1}\right\|}{r_{\beta_{n}}} \\
& +\left\|y_{n+1}-y_{n}\right\| \\
\leq & \left|r_{n+1}-r_{n}\right| M_{2}+\left\|y_{n+1}-y_{n}\right\|,
\end{aligned}
$$

where $M_{2}>\sup _{n \geq 1}\left\{\left\|y_{n+1}-J_{r_{\beta_{n}}}\left(1-r_{\beta_{n}} A\right) y_{n+1}\right\| / r_{\beta_{n}}\right\}, r_{\alpha_{n}}=$ $\min \left\{r_{n+1}, r_{n}\right\}$, and $r_{\beta_{n}}=\max \left\{r_{n+1}, r_{n}\right\}$. Hence from (69) and (74) we have

$$
\begin{aligned}
\left\|y_{n+1}-y_{n}\right\|= & \| \alpha_{n} f\left(y_{n}\right)+\left(1-\alpha_{n}\right) S z_{n}-\alpha_{n-1} f\left(y_{n-1}\right) \\
& +\left(1-\alpha_{n-1}\right) S z_{n-1} \| \\
= & \|\left(\alpha_{n}-\alpha_{n-1}\right)\left(f\left(y_{n-1}\right)-S z_{n-1}\right) \\
& +\left(1-\alpha_{n}\right)\left(S z_{n}-S z_{n-1}\right) \| \\
& +\alpha_{n}\left\|f\left(y_{n}\right)-f\left(y_{n-1}\right)\right\| \\
\leq & \left|\alpha_{n}-\alpha_{n-1}\right|\left\|f\left(y_{n-1}\right)-S z_{n-1}\right\| \\
& +\left(1-\alpha_{n}\right)\left\|S z_{n}-S z_{n-1}\right\| \\
& +\alpha_{n} r\left\|y_{n}-y_{n-1}\right\| \\
\leq & \left|\alpha_{n}-\alpha_{n-1}\right| M_{3}+\left(1-\alpha_{n}\right)\left\|z_{n}-z_{n-1}\right\| \\
& +\alpha_{n} r\left\|y_{n}-y_{n-1}\right\| \\
\leq & \left|\alpha_{n}-\alpha_{n-1}\right| M_{3}+\left|r_{n}-r_{n-1}\right| M_{2} \\
& +\left[1-\alpha_{n}(1-r)\right]\left\|y_{n}-y_{n-1}\right\|,
\end{aligned}
$$

where $M_{3}>\sup _{n \geq 1}\left\{\left\|f\left(y_{n}\right)-S z_{n}\right\|\right\}$. It follows from Lemma 4 , (ii), and (iii) that $\left\|y_{n+1}-y_{n}\right\| \rightarrow 0$.

Again from Lemmas 3 and 12, we obtain

$$
\begin{aligned}
\left\|y_{n+1}-z\right\|^{q}= & \| \alpha_{n}\left(f\left(y_{n}\right)-z\right) \\
& +\left(1-\alpha_{n}\right)\left(S T_{n} y_{n}-z\right) \|^{q} \\
\leq & \left(1-\alpha_{n}\right)\left\|T_{n} y_{n}-z\right\|^{q}+q \alpha_{n} \\
& \times\left\langle f\left(y_{n}\right)-z, j_{q}\left(y_{n+1}-z\right)\right\rangle . \\
\leq & \left\|T_{n} y_{n}-z\right\|^{q}+q \alpha_{n} M_{4} \\
\leq & \left\|y_{n}-z\right\|^{q}-r_{n}\left(\alpha q-r_{n}^{q-1} C_{q}\right)\left\|A y_{n}-A z\right\|^{q} \\
& -\phi_{q}\left(\left\|y_{n}-r_{n} A y_{n}-T_{n} y_{n}+r_{n} A z\right\|\right)+q \alpha_{n} M_{4},
\end{aligned}
$$

where $M_{4}>\sup _{n \geq 1}\left\{\left\langle f\left(y_{n}\right)-z, j_{q}\left(y_{n+1}-z\right)\right\rangle\right\}$. It follows immediately from (76) that

$$
\lim _{n \rightarrow \infty}\left\|A y_{n}-A z\right\|=\lim _{n \rightarrow \infty}\left\|y_{n}-r_{n} A y_{n}-T_{n} y_{n}+r_{n} A z\right\|=0 .
$$

Hence we obtain that

$$
\lim _{n \rightarrow \infty}\left\|T_{n} y_{n}-y_{n}\right\|=0 .
$$

By condition (iii), there exists $\varepsilon>0$ such that $r_{n} \geq \varepsilon$ for all $n \geq 1$. Then, by Lemma 12 , we get

$$
\lim _{n \rightarrow \infty}\left\|T_{\varepsilon} y_{n}-y_{n}\right\| \leq \lim _{n \rightarrow \infty} 2\left\|T_{n} y_{n}-y_{n}\right\|=0 .
$$


Step 1. We show $\lim _{n \rightarrow \infty}\left\|S T_{\varepsilon} y_{n}-y_{n}\right\|=0$.

From (73), (78), (79), and (ii), we have

$$
\begin{aligned}
\left\|S T_{\varepsilon} y_{n}-y_{n}\right\| \leq & \left\|S T_{\varepsilon} y_{n}-S T_{n} y_{n}\right\|+\left\|S T_{n} y_{n}-y_{n}\right\| \\
\leq & \left\|T_{\varepsilon} y_{n}-T_{n} y_{n}\right\|+\left\|S T_{n} y_{n}-y_{n}\right\| \\
\leq & \left\|T_{\varepsilon} y_{n}-y_{n}\right\|+\left\|y_{n}-T_{n} y_{n}\right\| \\
& +\left\|S T_{n} y_{n}-y_{n+1}\right\|+\left\|y_{n+1}-y_{n}\right\| \\
\leq & \left\|T_{\varepsilon} y_{n}-y_{n}\right\|+\left\|y_{n}-T_{n} y_{n}\right\| \\
& +\alpha_{n}\left\|f\left(y_{n}\right)-S T_{n} y_{n}\right\|+\left\|y_{n+1}-y_{n}\right\| \\
& \longrightarrow 0 .
\end{aligned}
$$

Lemmas 7 and 13 imply that

$$
\omega_{w}\left(y_{n}\right) \subset F\left(S T_{\varepsilon}\right)=F(S) \bigcap F\left(T_{\varepsilon}\right) .
$$

Next we prove that

$$
\limsup _{n \rightarrow \infty}\left\langle f(z)-z, j_{q}\left(y_{n}-z\right)\right\rangle \leq 0 .
$$

Equivalently (should $\left\|y_{n}-z\right\| \neq 0$ ), we need to prove that

$$
\limsup _{n \rightarrow \infty}\left\langle f(z)-z, j\left(y_{n}-z\right)\right\rangle \leq 0 .
$$

To this end, let $z_{t}$ satisfy $z_{t}=t f\left(z_{t}\right)+(1-t) S T_{\varepsilon} z_{t}$. By Xu's Theorem 4.1 [26], we get $z_{t} \rightarrow z \in F\left(S T_{\varepsilon}\right)$ as $t \rightarrow 0$, which $z$ is the unique solution of the variational inequality:

$$
\langle f(z)-z, j(x-z)\rangle \leq 0, \quad \forall x \in F\left(S T_{\varepsilon}\right) .
$$

Using subdifferential inequality, we deduce that

$$
\begin{aligned}
\left\|z_{t}-y_{n}\right\|^{2}= & t\left\langle f\left(z_{t}\right)-y_{n}, j\left(z_{t}-y_{n}\right)\right\rangle \\
& +(1-t)\left\langle S T_{\varepsilon} z_{t}-y_{n}, j\left(z_{t}-y_{n}\right)\right\rangle \\
= & t\left\langle f\left(z_{t}\right)-z_{t}, j\left(z_{t}-y_{n}\right)\right\rangle \\
& +t\left\langle z_{t}-y_{n}, j\left(z_{t}-y_{n}\right)\right\rangle \\
& +(1-t)\left\langle S T_{\varepsilon} z_{t}-S T_{\varepsilon} y_{n}, j\left(z_{t}-y_{n}\right)\right\rangle \\
& +(1-t)\left\langle S T_{\varepsilon} y_{n}-y_{n}, j\left(z_{t}-y_{n}\right)\right\rangle \\
\leq & t\left\langle f\left(z_{t}\right)-z_{t}, j\left(z_{t}-y_{n}\right)\right\rangle+t\left\|z_{t}-y_{n}\right\|^{2} \\
& +(1-t)\left\|z_{t}-y_{n}\right\|^{2}+(1-t) \\
& \times\left\|S T_{\varepsilon} y_{n}-y_{n}\right\|\left\|z_{t}-y_{n}\right\| \\
\leq & t\left\langle f\left(z_{t}\right)-z_{t}, j\left(z_{t}-y_{n}\right)\right\rangle \\
& +\left\|z_{t}-y_{n}\right\|^{2}+\left\|S T_{\varepsilon} y_{n}-y_{n}\right\|\left\|z_{t}-y_{n}\right\|
\end{aligned}
$$

which implies that

$$
\left\langle f\left(z_{t}\right)-z_{t}, j\left(y_{n}-z_{t}\right)\right\rangle \leq \frac{\left\|S T_{\varepsilon} y_{n}-y_{n}\right\|}{t}\left\|z_{t}-y_{n}\right\| .
$$

Using (80), taking the upper limit as $n \rightarrow \infty$ firstly and then as $t \rightarrow 0$ in (86), we have

$$
\limsup _{t \rightarrow 0} \limsup _{n \rightarrow \infty}\left\langle f\left(z_{t}\right)-z_{t}, j\left(y_{n}-z_{t}\right)\right\rangle \leq 0 .
$$

Since $E$ is a uniformly smooth Banach space, we have the duality mapping $j$ is norm-to-norm uniformly on any bounded subset of $E$, which ensures that the limits $\limsup \sup _{t \rightarrow 0}$ and $\limsup \operatorname{sum}_{n \rightarrow \infty}$ are interchangeable, and we have

$$
\limsup _{n \rightarrow \infty}\left\langle f(z)-z, j\left(y_{n}-z\right)\right\rangle \leq 0 \text {. }
$$

Finally, we show $\left\|y_{n}-z\right\| \rightarrow 0$.

By Lemma 3 and the fact that $a b \leq(1 / q) a^{q}+((q-$ $1) / q) b^{q /(q-1)}$, we get

$$
\begin{aligned}
\left\|y_{n+1}-z\right\|^{q}= & \left\|\alpha_{n} f\left(y_{n}\right)+\left(1-\alpha_{n}\right) S T_{n} y_{n}-z\right\|^{q} \\
= & \left\langle\alpha_{n} f\left(y_{n}\right)+\left(1-\alpha_{n}\right) S T_{n} y_{n}\right. \\
& \left.-z, j_{q}\left(y_{n+1}-z\right)\right\rangle \\
= & \alpha_{n}\left\langle f\left(y_{n}\right)-f(z), j_{q}\left(y_{n+1}-z\right)\right\rangle \\
& +\alpha_{n}\left\langle f(z)-z, j_{q}\left(y_{n+1}-z\right)\right\rangle \\
& +\left(1-\alpha_{n}\right)\left\langle S T_{n} y_{n}-z, j_{q}\left(y_{n+1}-z\right)\right\rangle \\
\leq & \alpha_{n}\left\|f\left(y_{n}\right)-f(z)\right\|\left\|y_{n+1}-z\right\|^{q-1} \\
& +\alpha_{n}\left\langle f(z)-z, j_{q}\left(y_{n+1}-z\right)\right\rangle \\
& +\left(1-\alpha_{n}\right)\left\|y_{n}-z\right\|\left\|y_{n+1}-z\right\|^{q-1} \\
\leq & \alpha_{n} r\left\|y_{n}-z\right\|\left\|y_{n+1}-z\right\|^{q-1} \\
& +\alpha_{n}\left\langle f(z)-z, j_{q}\left(y_{n+1}-z\right)\right\rangle+\left(1-\alpha_{n}\right) \\
& \times\left\|y_{n}-z\right\|\left\|y_{n+1}-z\right\|^{q-1} \\
\leq & {\left[1-\alpha_{n}(1-r)\right]\left\|y_{n}-z\right\|\left\|y_{n+1}-z\right\|^{q-1} } \\
& +\alpha_{n}\left\langle f(z)-z, j_{q}\left(y_{n+1}-z\right)\right\rangle \\
& {\left[1-\alpha_{n}(1-r)\right] \frac{1}{q}\left\|y_{n}-z\right\|^{q}+\frac{q-1}{q} } \\
& \left\|y_{n+1}-z\right\|^{q}+\alpha_{n}\left\langle f(z)-z, j_{q}\left(y_{n+1}-z\right)\right\rangle, \\
& \\
& \\
&
\end{aligned}
$$

which implies that

$$
\begin{aligned}
\left\|y_{n+1}-z\right\|^{q} \leq & {\left[1-\alpha_{n}(1-r)\right]\left\|y_{n}-z\right\|^{q} } \\
& +q \alpha_{n}\left\langle f(z)-z, j_{q}\left(y_{n+1}-z\right)\right\rangle .
\end{aligned}
$$

Apply Lemma 4 to (90) to conclude $y_{n} \rightarrow z$ as $n \rightarrow \infty$. This completes the proof. 
Remark 17. Theorem 16 improves and extends Theorem 3.7 of López et al. [18] in the following ways:

(i) from the problem of finding an element of $(A+B)^{-1}(0)$ to the problem of finding an element of $(A+B)^{-1}(0) \cap$ $F(S)$,

(ii) from a fixed element $u$ in $E$ to a contractive mapping $f$.

Remark 18. Theorem 16 improves and extends Theorem 2.1 of Zhang et al. [7] in the following ways:

(i) from Hilbert spaces to uniformly convex and $q$ uniformly smooth Banach spaces,

(ii) from a fixed element $u$ in $E$ to a contractive mapping $f$,

(iii) from a fixed positive number $\lambda$ to a positive sequence $\left\{r_{n}\right\}$.

As a direct consequence of Theorem 16, we obtain the following result.

Corollary 19. Let $H$ be a Hilbert space. Let $A: H \rightarrow H$ be $\alpha$-inverse strongly monotone, let $B: H \rightarrow 2^{H}$ be maximal monotone, let $f: E \rightarrow$ E ber-contractive, and let $S: H \rightarrow H$ be nonexpansive. Assume that $F(S) \cap(A+B)^{-1}(0) \neq \emptyset$. We define a sequence $\left\{x_{n}\right\}$ by the perturbed iterative scheme:

$$
\begin{aligned}
x_{n+1}= & \alpha_{n} f\left(x_{n}\right)+\left(1-\alpha_{n}\right) \\
& \times S\left(J_{r_{n}}\left(x_{n}-r_{n}\left(A x_{n}+a_{n}\right)\right)+b_{n}\right), \quad \forall n \geq 1,
\end{aligned}
$$

where $J_{r_{n}}=\left(I+r_{n} B\right)^{-1}$. Assume that $\left\{\alpha_{n}\right\} \subset[0,1],\left\{r_{n}\right\} \subset$ $(0,+\infty)$, and $\left\{a_{n}\right\},\left\{b_{n}\right\} \subset H$ satisfying the following conditions:

(i) $\sum_{n=1}^{\infty}\left\|a_{n}\right\|<\infty$ and $\sum_{n=1}^{\infty}\left\|b_{n}\right\|<\infty$;

(ii) $\sum_{n=1}^{\infty} \alpha_{n}=\lim _{n \rightarrow \infty} \alpha_{n}=0$ and $\sum_{n=1}^{\infty}\left|\alpha_{n+1}-\alpha_{n}\right|<$ $\infty$;

(iii) $0<\liminf _{n \rightarrow \infty} r_{n} \leq \limsup _{n \rightarrow \infty} r_{n}<2 \alpha$ and $\sum_{n=1}^{\infty}\left|r_{n+1}-r_{n}\right|<\infty$.

Then $\left\{x_{n}\right\}$ converges strongly to some point $z \in F(S) \cap$ $(A+B)^{-1}(0)$, which is the unique solution of the variational inequality $\langle f(z)-z, p-z\rangle \leq 0, \forall p \in F(S) \cap(A+B)^{-1}(0)$.

\section{Conflict of Interests}

The authors declare that there is no conflict of interests regarding the publication of this paper.

\section{Acknowledgments}

This research was supported by the National Science Foundation of China (11071169) and the Innovation Program of Shanghai Municipal Education Commission (09ZZ133).

\section{References}

[1] M. A. Noor and K. I. Noor, "Sensitivity analysis for quasi-variational inclusions," Journal of Mathematical Analysis and Applications, vol. 236, no. 2, pp. 290-299, 1999.

[2] V. F. Demyanov, G. E. Stavroulakis, L. N. Polyakova, and P. D. Panagiotopoulos, Quasidifferentiability and Nonsmooth Modelling in Mechanics, Engineering and Economics, vol. 10 of Nonconvex Optimization and Its Applications, Kluwer, Dordrecht, The Netherlands, 1996.

[3] S.-S. Chang, "Existence and approximation of solutions for setvalued variational inclusions in Banach space," Nonlinear Analysis, Theory, Methods \& Applications, vol. 47, no. 1, pp. 583-594, 2001.

[4] S. S. Chang, "Set-valued variational inclusions in Banach spaces," Journal of Mathematical Analysis and Applications, vol. 248, no. 2, pp. 438-454, 2000.

[5] M. A. Noor, "Generalized set-valued variational inclusions and resolvent equations," Journal of Mathematical Analysis and Applications, vol. 228, no. 1, pp. 206-220, 1998.

[6] P. Hartman and G. Stampacchia, "On some non-linear elliptic differential-functional equations," Acta Mathematica, vol. 115, no. 1, pp. 271-310, 1966.

[7] S. S. Zhang, J. Lee, and C. K. Chan, "Algorithms of common solutions to quasi variational inclusion and fixed point problems," Applied Mathematics and Mechanics, vol. 29, no. 5, pp. 571-581, 2008.

[8] H. Manaka and W. Takahashi, "Weak convergence theorems for maximal monotone operators with nonspreading mappings in a Hilbert space," Cubo, vol. 13, no. 1, pp. 11-24, 2011.

[9] S. Kamimura and W. Takahashi, "Approximating solutions of maximal monotone operators in Hilbert spaces," Journal of Approximation Theory, vol. 106, no. 2, pp. 226-240, 2000.

[10] S. Y. Cho, W. Li, and S. M. Kang, "Convergence analysis of an iterative algorithm for monotone operators," Journal of Inequalities and Applications, vol. 2013, article 199, 2013.

[11] W. Takahashi, "Strong convergence theorems for maximal and inverse-strongly monotone mappings in Hilbert spaces and applications," Journal of Optimization Theory and Applications, vol. 157, no. 3, pp. 781-802, 2013.

[12] Y. Yao and J.-C. Yao, "On modified iterative method for nonexpansive mappings and monotone mappings," Applied Mathematics and Computation, vol. 186, no. 2, pp. 1551-1558, 2007.

[13] S. Wang, "A modified regularization method for the proximal point algorithm," Journal of Applied Mathematics, vol. 2012, Article ID 567948, 14 pages, 2012.

[14] L. Zhao, S.-S. Chang, and M. Liu, "Viscosity approximation algorithms of common solutions for fixed points of infinite nonexpansive mappings and quasi-variational inclusion problems," Communications on Applied Nonlinear Analysis, vol. 15, no. 3, pp. 83-98, 2008.

[15] K. Aoyama, H. Iiduka, and W. Takahashi, "Weak convergence of an iterative sequence for accretive operators in Banach spaces," Fixed Point Theory and Applications, vol. 2006, Article ID 35390, 13 pages, 2006.

[16] H. Zegeye and N. Shahzad, "Strong convergence theorems for a common zero of a finite family of $m$-accretive mappings," Nonlinear Analysis, Theory, Methods \& Applications, vol. 66, no. 5, pp. 1161-1169, 2007.

[17] H. Zegeye and N. Shahzad, "Strong convergence theorems for a common zero point of a finite family of $\alpha$-inverse strongly 
accretive mappings," Journal of Nonlinear and Convex Analysis, vol. 9, no. 1, pp. 95-104, 2008.

[18] G. López, V. Martín-Márquez, F. H. Wang, and H. K. Xu, "Forward-backward splitting methods for accretive operators in Banach spaces," Abstract and Applied Analysis, vol. 2012, Article ID 109236, 25 pages, 2012.

[19] S. Y. Cho, X. L. Qin, and L. Wang, "Iterative algorithms with errors for zero points of $m$-accretive operators," Fixed Point Theory and Applications, vol. 2013, article 148, 2013.

[20] H.-K. Xu, "Inequalities in Banach spaces with applications," Nonlinear Analysis, Theory, Methods \& Applications, vol. 16, no. 12, pp. 1127-1138, 1991.

[21] K. Aoyama, Y. Kimura, W. Takahashi, and M. Toyoda, "Approximation of common fixed points of a countable family of nonexpansive mappings in a Banach space," Nonlinear Analysis, Theory, Methods \& Applications, vol. 67, no. 8, pp. 2350-2360, 2007.

[22] K. K. Tan and H. K. Xu, "Approximating fixed points of nonexpansive mappings by the Ishikawa iteration process," Journal of Mathematical Analysis and Applications, vol. 178, no. 2, pp. 301-308, 1993.

[23] F. E. Browder, "Semicontractive and semiaccretive nonlinear mappings in Banach spaces," Bulletin of the American Mathematical Society, vol. 74, pp. 660-665, 1968.

[24] R. E. Bruck, "A simple proof of the mean ergodic theorem for nonlinear contractions in Banach spaces," Israel Journal of Mathematics, vol. 32, no. 2-3, pp. 107-116, 1979.

[25] W. Kaczor, "Weak convergence of almost orbits of asymptotically nonexpansive commutative semigroups," Journal of Mathematical Analysis and Applications, vol. 272, no. 2, pp. 565574, 2002.

[26] H.-K. Xu, "Viscosity approximation methods for nonexpansive mappings," Journal of Mathematical Analysis and Applications, vol. 298, no. 1, pp. 279-291, 2004. 


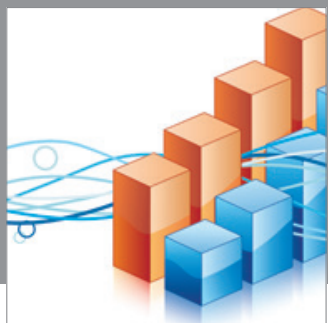

Advances in

Operations Research

mansans

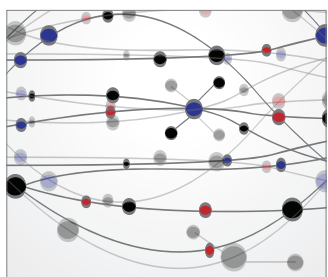

The Scientific World Journal
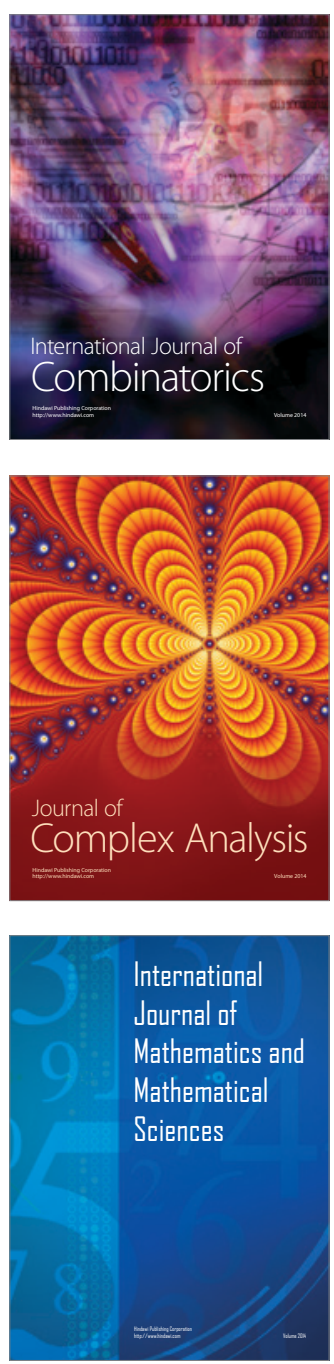
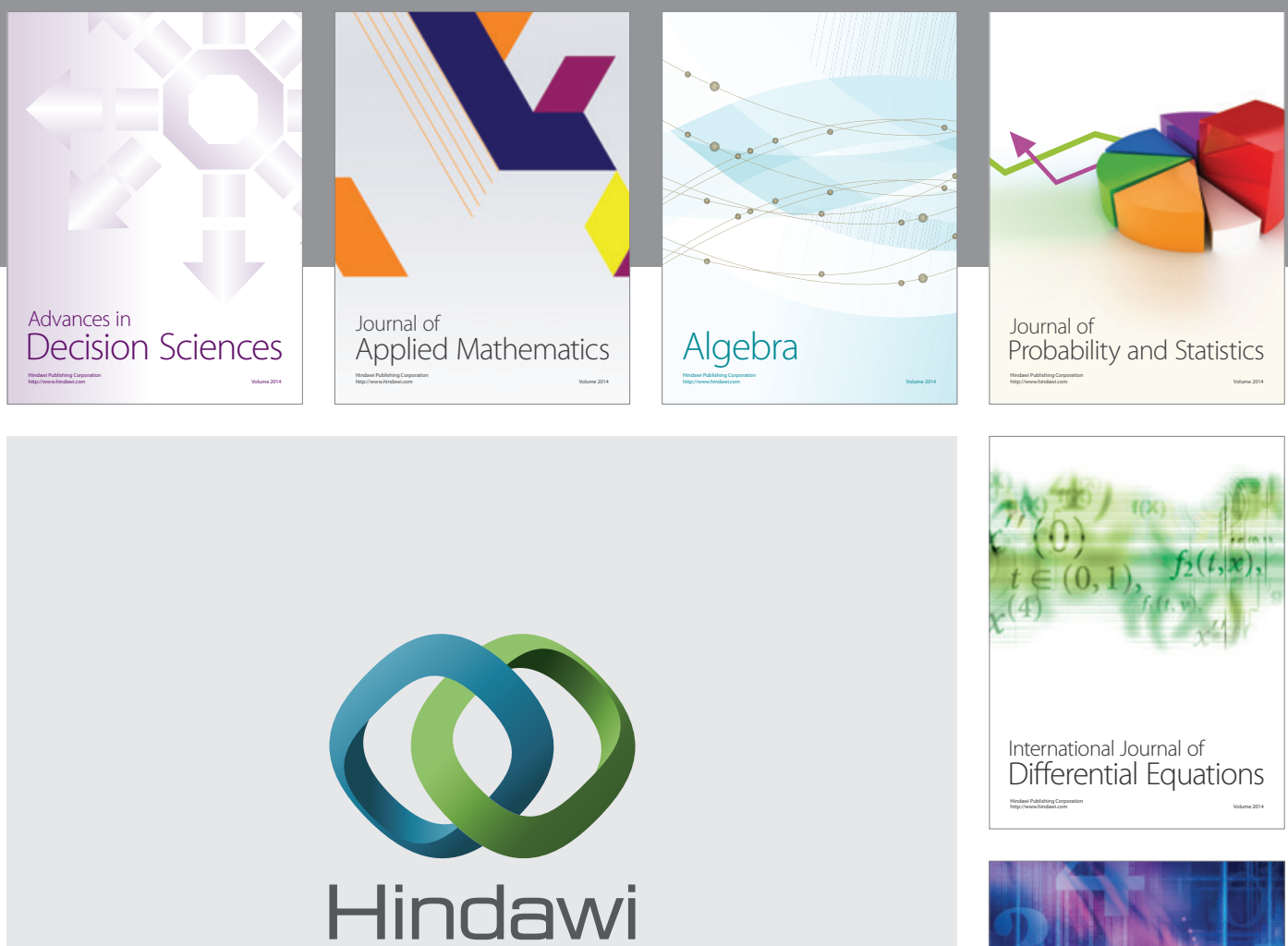

Submit your manuscripts at http://www.hindawi.com
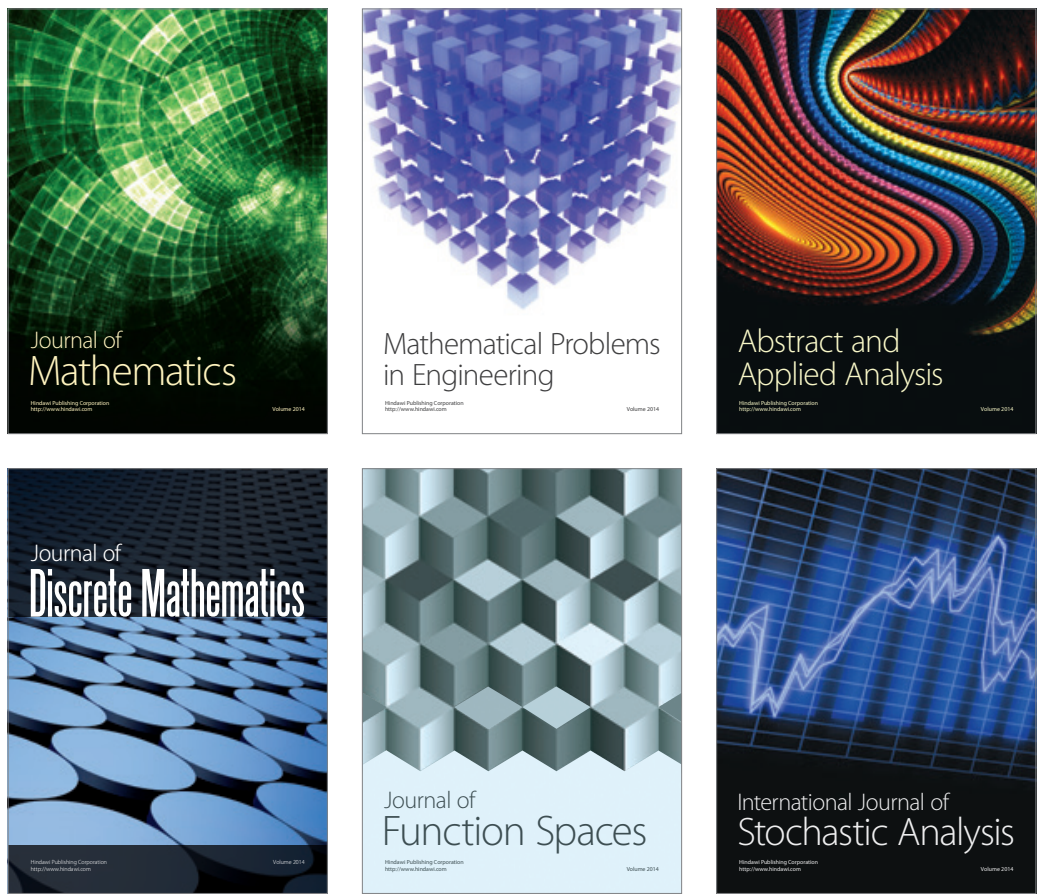

Journal of

Function Spaces

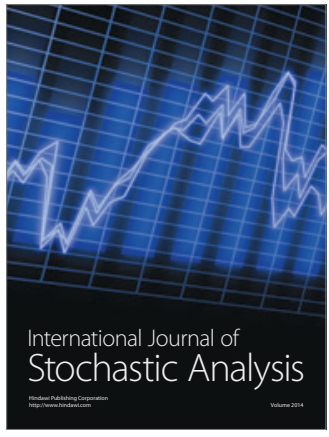

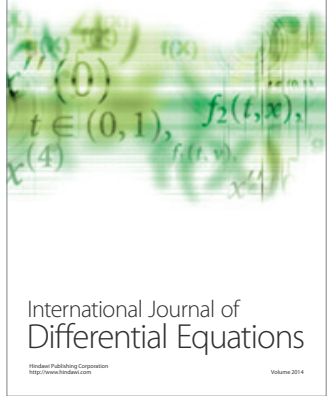
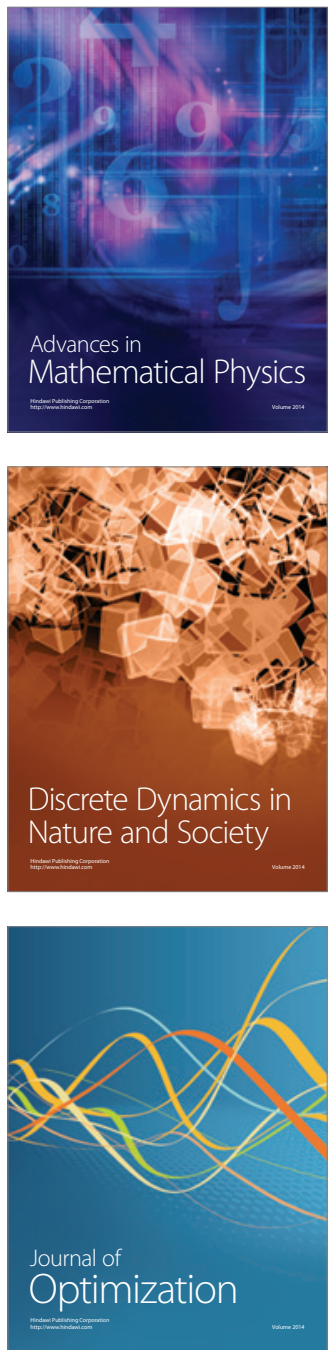